\title{
On the record...
}

\section{Interview with Jenni Irish- Qhobosheane}

\begin{abstract}
Since the 2009 national election, minister of police, Nathi Mthethwa, has been reorganising and strengthening the national secretariat of police. The existence of this body is constitutionally mandated. Gareth Newham spoke to the new national secretary of police, Jenni Irish-Qhobosheane, on 25 February 2010.
\end{abstract}

Gareth Newham (GN): What are the core functions of the Secretariat?

Jenni Irish-Qhobosheane (JIQ): Essentially, the core function is to support the minister of police to fulfil his constitutional mandate and responsibility. This includes determining the policy and strategic direction of the police, securing its budget and overseeing expenditure. It is for this reason that the Secretariat has a strong policy and research role to play in support of the minister. Ultimately it is to provide civilian oversight over the police. The minister has added a function, which is to build and maintain partnerships. So there are three key functions of the Secretariat: to advise the minister on policy and conduct research to inform the minister's decisionmaking; to conduct civilian oversight of the police through monitoring and evaluation; and thirdly, to fulfil these functions through partnerships. The minister also wants the Secretariat to play a role in the drafting of legislation for the police, which used to be done only by the SAPS.

GN: Between 1994 and 1999 the Secretariat was seen as a powerful structure and played an important policy role. However, after 1999 the post of the national secretary was downgraded, and for the past decade many people have seen the National Secretariat as having a very limited function. Now the post of the national secretary has been upgraded and there are moves to substantially strengthen the structure. What has changed?
JIQ: The changes were twofold. Firstly, government became increasingly concerned with the quality of service delivery and there was a strong emphasis on strengthening the monitoring and evaluation capacity of government. Secondly, the minister himself has been the driving force behind the change to the Secretariat. In the period following the April 2009 national elections he identified a range of gaps and weaknesses in policing. This was partly because of concerns about the police that were being raised in parliament. Also, there were a number of crucial issues in the 1998 White Paper on Safety and Security that had not been taken forward. It was for these reasons that the need arose to strengthen the capacity of the Secretariat. The role of the Secretariat also needs to be entrenched, and so we are in the process of drafting legislation to give the Secretariat the authority it needs. This will go before parliament this year. Currently we are also looking at how we align the Provincial Secretariats' work with the National Secretariat, given that policing is a national competency in South Africa. We are also going to ensure that the National Secretariat has people of quality who can perform the necessary functions that are required. The minister wants to make sure that the capacity of the National Secretariat is entrenched so that it does not again become weakened, as was the case in the past.

GN: What is the vision that is driving the current thinking of changing the police from a 'service' to a 'force'?

JIQ: Essentially it can be explained in terms of three things, accountability, communication and 
coordination. The issue of accountability is most important as there is a need to create clear line functions in the police so that each person knows who is in charge, who they are accountable to, and who is accountable to them. This will also help the public know who has authority and responsibility. This is also a way of improving discipline in the police, which is an important matter. It must also be understood that the approach is not just about making the police tougher on criminals. The reorganisation and strengthening of the National Secretariat and the Independent Complaints Directorate (ICD) must be seen in this context. We are aware that there may be challenges as a result of changing the police. To minimise the negative impact of these challenges, the external oversight structures are being strengthened. The minister has thought through these issues carefully. It is not just a kneejerk reaction.

GN: What are the most important police oversight challenges facing the Secretariat?

JIQ: There are a number of challenges. The past backward slide of the Secretariat is not just the fault of the SAPS. It was also about the capacity of the Secretariat. This is the biggest challenge we face. We need to bring in the right people but we also need to draw on the expertise that is out there in society. There are many people in various organisations that have a lot of valuable experience and insight and we want to work in partnership with them to assist the Secretariat in fulfilling its functions. It is for this reason that we intend to establish reference groups consisting of representatives from civil society to engage with the Secretariat.

Another challenge is getting the police to understand the functions of the Secretariat. We need to recapture some of the terrain that the Secretariat held in its early days. This is a daily challenge. Addressing this challenge requires the support and vision of our Executive Authority (the minister). Fortunately this does exist and we believe that legislation will help. We also need parliament to hold the Secretariat accountable for its oversight role. Another key challenge is that the Secretariat will have to remain focused on the broad issues, or the structural issues, that impact on police transformation and not be distracted by the different individual issues that emerge.

Over the past few years the Secretariat has tried to investigate each complaint against the police that was brought before it. However, these complaints usually refer to police service delivery and fall within the responsibility of operational policing. We need to take cognisance of the service delivery and other complaints that are made against the police, but our focus needs to be on the structural and policy shortcomings that led to the complaint, and not only the complaint itself.

We are not going to establish a massive Secretariat. Rather, we want to have a streamlined body that is effective. This will require that we clearly communicate with the public that we are not a complaints office. We have to keep a clear line between our role, which is to focus on civilian oversight and policy advice; and the role of the police, which is to focus on operations. There mustn't be encroachment on each other's core functions. This will be a challenge that we must always keep in mind.

Another important challenge is developing a clear implementation plan. Once the legislation is finalised and our functions are clear, we will be in a better position to plan our activities. We will need to keep our house in order if we are to succeed in holding the police accountable for the implementation of their plans.

GN: Could you explain the issue of separating policy issues from operational issues by speaking to practical examples? There will be specific incidents that make it into the media that will be indicative of a larger problem in the police. A couple of examples that come to mind include the recent arrest of the UCT student by members of the SAPS VIP unit that were part of the presidential cavalcade; and the accusation that evidence is going missing from the police forensic laboratories.

JIQ: The minister is aware of these issues and will usually do a couple of things. He may order a 
specific investigation into the incident for the purposes of uncovering the facts behind it. If police officers have broken the law they will be subject to criminal charges. On the other hand, he will also instruct the Secretariat to look into the reasons behind the incident. Are there policy or other organisational shortcomings that have resulted in this incident? He will then expect the Secretariat to come up with recommendations on how it could be addressed more broadly. He may also request the internal SAPS Inspectorate to investigate a problem and give him feedback. He does this quite regularly. However, the UCT example cited was purely an operational issue and was dealt with at this level by the minister and national commissioner.

GN: Finally, may I ask you to briefly tell our readers something about your background before you were appointed the national secretary for the Police Civilian Secretariat?

JIQ: I am from KwaZulu Natal and I was politically active in youth structures during the 1980s and early 1990s. During this time I also started monitoring political violence for the Network of Independent Monitors (NIM). These experiences brought me in contact with the police and I became aware of the challenges associated with policing and private security. During the 1990s my late husband was among those from the African National Congress (ANC) structures who were integrated into the SAPS as part of its transformation and it was also through him that I obtained good insight into policing. In 1999 he left the police and we set up a consultancy. Our first job in fact was for the National Secretariat for Safety and Security, as it was then called. Most of our consulting work was focused on research and facilitation in relation to policing. We worked for a variety of stakeholders from government, civil society and the private sector. Increasingly we started working on policing in Africa and spent time in Angola, the Democratic Republic of Congo (DRC), Mozambique and Sierra Leone. After a time my husband became ill and it became impossible to travel. It was at this time, in 2006, that I was appointed to head up the Business Robbery Strategy Project at Business Against
Crime (BAC). I was then offered this position in 2009 on a fixed term contract.

GN: Thank you for taking the time to be interviewed and for sharing your insights with SA Crime Quarterly. 